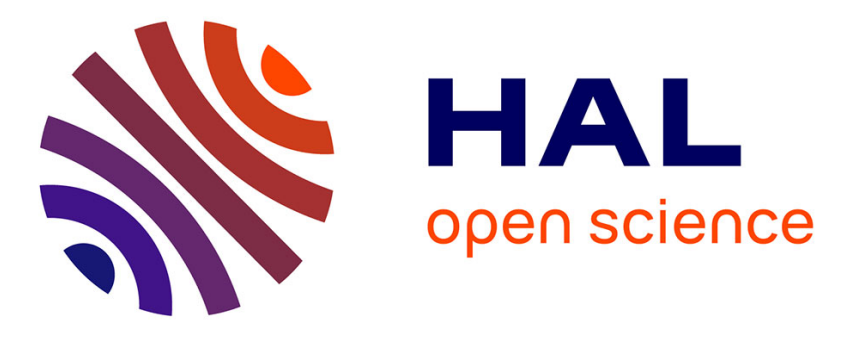

\title{
Altered lignin composition in transgenic tobacco expressing O-methyltransferase sequences in sense and antisense orientation
}

Rossitza Atanassova, Noëlle Favet, Françoise Martz, Brigitte Chabbert, Marie-Thérèse Tollier, Bernard B. Monties, Bernard Fritig, Michel Legrand

\section{To cite this version:}

Rossitza Atanassova, Noëlle Favet, Françoise Martz, Brigitte Chabbert, Marie-Thérèse Tollier, et al.. Altered lignin composition in transgenic tobacco expressing O-methyltransferase sequences in sense and antisense orientation. Plant Journal, 1995, 8 (4), pp.465-477. 10.1046/j.1365313X.1995.8040465.x . hal-02715285

\section{HAL Id: hal-02715285 \\ https://hal.inrae.fr/hal-02715285}

Submitted on 12 Aug 2021

HAL is a multi-disciplinary open access archive for the deposit and dissemination of scientific research documents, whether they are published or not. The documents may come from teaching and research institutions in France or abroad, or from public or private research centers.
L'archive ouverte pluridisciplinaire HAL, est destinée au dépôt et à la diffusion de documents scientifiques de niveau recherche, publiés ou non, émanant des établissements d'enseignement et de recherche français ou étrangers, des laboratoires publics ou privés.

\section{(c)(1)}

Distributed under a Creative Commons Attribution| 4.0 International License 


\section{Altered lignin composition in transgenic tobacco expressing 0-methyltransferase sequences in sense and antisense orientation}

\author{
Rossitza Atanassova', Noëlle Favet', Françoise Martz', \\ Brigitte Chabbert², Marie-Thérèse Tollier?, \\ Bernard Monties' ${ }^{2}$, Bernard Fritig' and Michel Lagrand"* \\ 'Institut de Biologie Moléculaire des Plantes du CNRS, \\ Université Louis Pasteur, 12, rue du Général Zimmer, \\ 67084 Strasbourg Cedex, France, and \\ ${ }^{2}$ Laboratoire de Chimie Biologique, INRA-INA PG, 78850 \\ Thiverval Grignon, France
}

\section{Summary}

The monomeric composition of tobacco lignin has been modified by genetic engineering. Sense or antisense expression of sequences encoding O-methyltransferase (OMT), a lignin biosynthetic enzyme, was shown to modulate enzyme activity. Tan constructs harboring the entire or a partial OMT cDNA were used. Populations of 20 transgenic plants per construct ware analyzed for OMT activity and compared with untransformed controls. As expected, expression of only the full-length sense construct led to an increase in OMT activity. An important reduction of activity was found in a variable number of plantlets from all other transgenic populations but the inhibition was sustained through the adult stage only in plants transformed with the complete cDNA. T-DNA genes were shown to be stably integrated into the tobacco genome and to be transmitted to the progeny. By using gene-specific probes, OMT inhibition in stems was correlated to a parallel disappearance of OMT transcripts originating from both the resident gene and the transgene. In contrast, transgene transcripts were detected in leaf tissues where the resident gene is poorly expressed, thus indicating that relative expression of the two OMT genes controls transcript turnover. In stems of inhibited plants, a marked decrease of syringyl units and the appearance of 5-hydroxy guaiacyl units were demonstrated. These two structural features are also characteristic of natural mutants of maize with an improved digestibility compared with wild lines. These data demonstrate the feasibility and the potential benefits of lignin manipulation.

\section{Introduction}

Lignin is the second most abundant organic compound on earth, after cellulose. It is a complex aromatic polymer which provides mechanical strength to plant cell walls and hydrophobicity to conducting vessels (Lewis and Yamamoto, 1990; Monties, 1989). In addition, lignin deposition is thought to represent a defense reaction against pathogen invasion (Legrand, 1983; Matern and Kneusel, 1988; Nicholson and Hammerschmidt, 1992; Vance et al., 1980). However, lignin may have a negative impact on the utilization of the biomass (Buxton and Russel, 1988; Dean and Eriksson, 1992; Whetten and Sederoff, 1991). During paper pulping, for example, lignin must be eliminated from wood by chemical treatments that are expensive and polluting. The quantity of lignin in forage crop is also negatively correlated to digestibility and appetence (Buxton and Russel, 1988; Jung and Vogel, 1986). Therefore the modification of lignin content and/or composition by genetic manipulation would be of great economic interest.

The phenylpropanoid pathway provides the building units of lignin (Figure 1). Lignin is a complex polymer arising from the dehydrogenative polymerization of the three monolignols, namely p-coumaryl alcohol, coniferyl alcohol and sinapyl alcohol (Grisebach, 1981). The two later monomers bear, respectively, one and two methyl groups introduced by 0 -diphenol-0-methyltransferases (OMT; EC 2.1.1.6). OMTs of angiosperm species, were considered as bifunctional since the same enzymes methylate both caffeic acid and 5-hydroxyferulic acid in vitro to yield ferulic acid and sinapic acid, respectively (Figure 1). Recently, it has been suggested that another enzyme, caffeoyl-coA 0-methyltransferase, is implicated in lignin biosynthesis (Ye et al., 1994) and the analysis of lignin from transgenic tobacco plants that we describe here, supports this hypothesis. After synthesis of the respective $\operatorname{co} A$ esters by $\operatorname{co} A$ ligases, reduction steps catalyzed by cinnamoyl-coA reductase (CCR) and cinnamyl alcohol dehydrogenase (CAD) lead to the corresponding alcohols. Consequently, angiosperm lignin contains both guaiacyl (coniferyl-derived) and syringyl (sinapyl-derived) units. This is in contrast to the situation in gymnosperm species, whose lignin is mainly constituted of guaiacyl units because their OMTs do not accept 5-hydroxyferulic acid as substrate (Kuroda et al., 1975). Hence, OMTs are regulatory enzymes controlling lignin content and composition.

Tobacco has been shown to possess two classes of OMTs differing by substrate specificities and expression patterns (Hermann et al., 1987; Jaeck et al., 1992; Legrand et al., 1978; Pellegrini et al., 1993). Class I OMT is highly expressed 


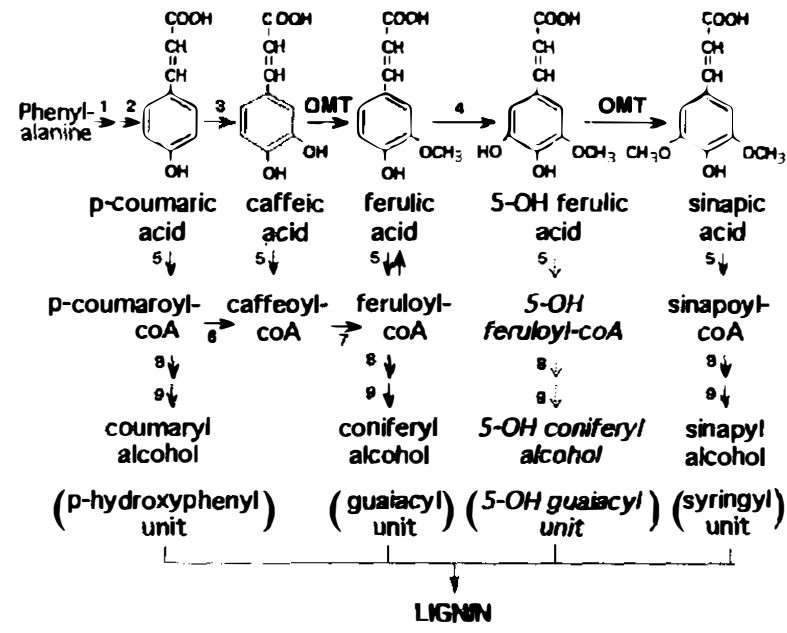

Figure 1. OMT-catalyzed reactions in the general phenylpropanoid pathway Nomenclature of units obtained after chemical degradation by thioacidolysis is indicated in brackets. Italics show the pathway from 5-OH ferulate to $5-\mathrm{OH}$ guaiacyl unit characteristic of transgenics with reduced OMT activity. 1, phenylalanine ammonia-lyase; 2 , cinnamate 4-hydroxylase 3. p-coumarate 3-hydroxylase; 4, ferulate 5-hydroxylase; 5, coA-ligase 6, p-coumaroyl-coA 3-hydroxylase; 7, caffeoyl-coA 0-methyltransferase; 8 , cinnamoyl-coA reductase; 9 . cinnamyl alcohol dehydrogenase.

in lignified tissues whereas class II OMTs are barely detectable in healthy plants but are strongly induced upon infection. Class I enzymes, specifically involved in lignin biosynthesis, have been cloned recently from several plant species (Bugos et al., 1991; Collazo et al., 1992; Dumas et al., 1992; Gowri et al., 1991; Poeydomenge et al., 1994) and a class II OMT clone has been isolated from tobacco (Pellegrini et al., 1993).

Mutants lines of maize, sorghum and pearl millet have been shown to have a reduced lignin content and better digestibility (Cherney et al., 1991). These mutants are called brown midrib $(\mathrm{bm})$ mutants because they show a characteristic brown pigmentation of lignified tissues. It has been shown that the bm 3 maize mutant has a reduced OMT activity (Grand et al., 1985) due to alterations of OMT gene (Vignols et al., 1995). The bm 6 mutant of sorghum bicolor has a depression in both OMT and CAD activities (Pillonel et al., 1991). Recently, an Arabidopsis mutant was shown to be affected in the ferulate 5-hydroxylation step and to have an altered lignin composition (Chapple et al., 1992). These findings suggest that a modulation of the activity of lignin biosynthetic enzymes by genetic engineering has the potential to change lignin biosynthesis in transgenic plants. A few attempts to repress OMT or CAD genes of tobacco by expressing antisense RNAs have been reported recently. Halpin et al. (1994) have demonstrated that transgenic tobacco with low CAD activity have lignin modified by the incorporation of cinnamyl aldehydes. The effects of antisense expression of a lucerne OMT gene (Ni et al., 1994) and of an aspen OMT gene (Dwivedi et al., 1994) on lignin biosynthesis of transgenic tobacco plants have also been investigated. The results of the two studies differed considerably from ours (see below), perhaps due to the heterologous nature of the cDNAs introduced in tobacco. Expression of the lucerne sequence led to a reduced lignin content without affecting monomer composition (Ni et al., 1994) whereas expression of the aspen sequence was claimed to slightly change lignin composition of transgenic tobacco (Dwivedi et al., 1994).

In this paper we have investigated the possibility of downregulating class I OMT expression in tobacco by expressing different parts of the homologous sequence in sense and antisense orientation. A total of 200 plants transformed with 10 different constructs were analyzed for OMT activity and compared with the control population. OMT modulation was obtained with every construct tested but with highly variable efficiency, as evidenced by the varying proportions of plants with elevated or reduced activity in the different transgenic populations. Inhibition was sustained through the adult stage only in plants transformed with the complete cDNA and, when a high level of OMT inhibition (less than 20\% residual activity) was achieved, the lignin composition was strongly modified. Total lignin content was not significantly affected but the novel lignin had a remarkably decreased content in syringyl units and contained a new building unit derived from 5-hydroxyferulic acid (one of the OMT substrates, see Figure 1). These features are also characteristic of lignin of bm3 mutants of maize (Lapierre et al., 1988) and the findings presented here demonstrate the suitability of OMT genes as targets for genetic manipulation of lignin quality.

\section{Results}

\section{Comparative efficiencies of the different OMT constructs}

The expression of several plant genes has been efficiently and specifically decreased by expressing their antisense counterpart (for review see Gray et al., 1992; Mol et al., 1990; Watson and Grierson, 1993). In the aforesaid studies, the expression of various gene fragments was proven to be effective: for instance, the entire gene sequence of chalcone synthase (Van der Krol et al., 1988), the 5' part of the polygalacturonase gene (Smith et al., 1988) or the $3^{\prime}$ part of a chalcone synthase gene (Van der Krol et al., 1990) have been used successfully. In other experiments, the expression of transgenes in sense orientation has also been shown to lead to the silencing of the endogenous gene (Flavell, 1994; Matzke and Matzke, 1993; Napoli et al., 1990).

Here, we used five different fragments of class I OMT cDNA (depicted in Figure 2) in sense or antisense orientation to modulate OMT activity in transgenic plants and to study, in turn, the consequences upon lignin biosynthesis. The T-DNA of the pFB8 binary vector (Figure 2) also carried the $\beta$-glucuronidase (uidA) gene that served as an internal 


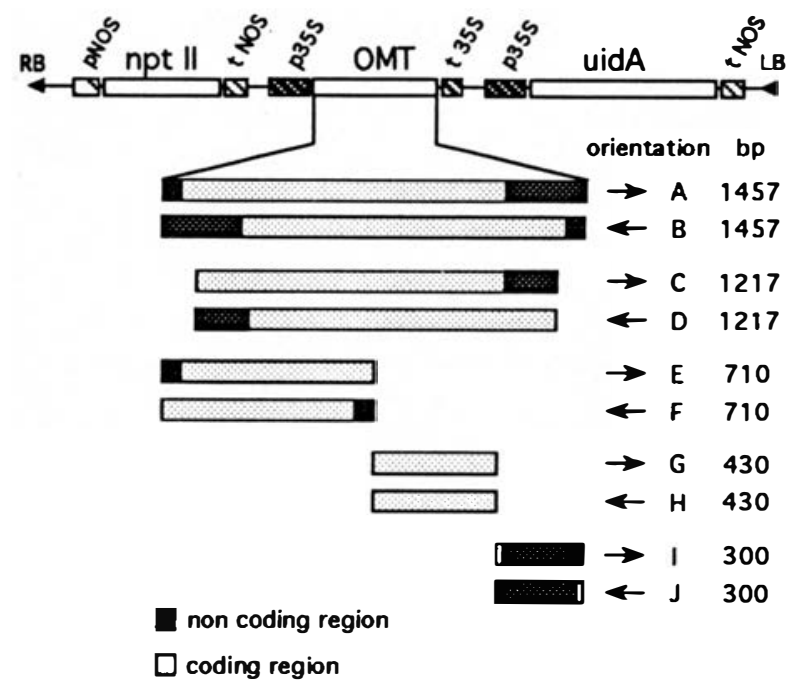

Figure 2. The pFBB binary vector and the sense and antisense constructs containing different fragments of OMT cDNA.

control gene with no homologous sequence in the plant genome. Twenty independent transformants selected on kanamycin medium were regenerated in each case. Twenty-one untransformed regenerants were also grown under the same conditions (but without kanamycin selection) and constituted the control population.

In fact, to evaluate the potential effects of gene transformation on endogenous gene expression, it is necessary to know the natural variability of gene expression in the control population. It has been reported previously that the basal level of OMT activity was highly variable in healthy tobacco leaves (Legrand et al., 1978). Class I OMT which is involved in lignin biosynthesis, has been shown to be specifically expressed in lignified tissues of stems (Jaeck et al., 1992) and therefore we have measured OMT activity in the basal part of the stems of control plants. The control population consisted of 215 -week-old untransformed, in vitro regenerated plants. The data are presented in Figure 3 and show important fluctuations in enzyme activity levels. The distribution of the values was proven to be Normal by Probit analysis, with a mean value of $2.7 \times 10^{-5}$ nkat $\mu \mathrm{g}^{-1}$ protein and a standard deviation of $1.2 \times 10^{-5}$ nkat $\mu \mathrm{g}^{-1}$ protein. Plants transformed with an empty plasmid (without OMT insert) were also generated and analyzed. An enzyme activity value of $3.7 \pm 1.7 \times$

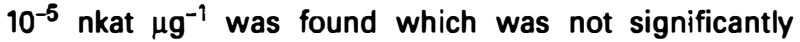
different as compared with untransformed plants. Therefore, the activity measured for each individual transformant was compared with the activity mean value calculated from the untransformed population.

OMT activities were measured in populations of 20 plants transformed with each of the 10 constructs depicted in Figure 2. The distribution of the values was found to be Normal as in the case of control population (Figure 3) and

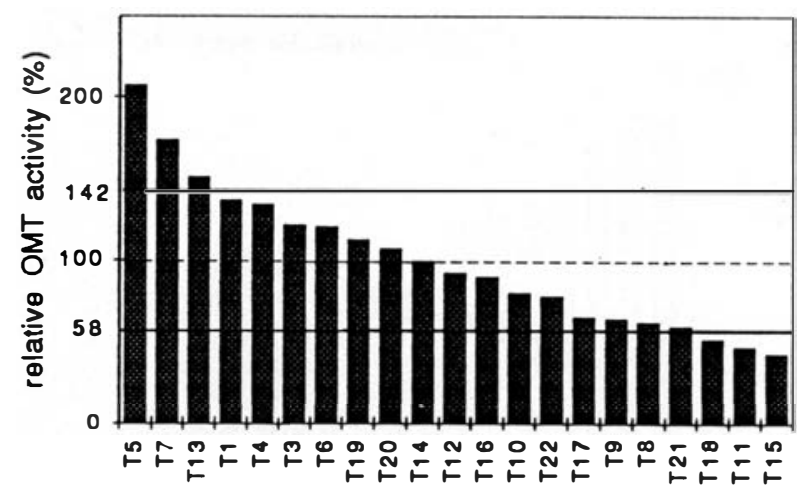

Figure 3. OMT activity in untransformed control plants.

The activity value of each individual is expressed as the percentage of the mean value of the population (dashed line). The two solid lines indicate the standard deviation.

in each population a number of individuals were found with activities significantly different from the controls. This is evidenced in Figure 4 by values higher or lower than the control standard deviations that are indicated by the two horizontal lines. The test of Student demonstrated that populations $A, B, C, D$ and $E$ differed from the control population at the $99 \%$ probability level. The other populations were not significantly different from the control, with the exception of population $\mathrm{J}$, which differed at the $95 \%$ level.

The above data show that the proportion of transgenics affected in OMT activity is highly variable and depends on the nature of the ectopic sequence. The full-length sequence was active in both orientations. The sense expression gave rise to 14 plants out of 20 with an increased activity ranging from 170 to $370 \%$ of the mean control value. One plant $\left(A_{17}\right)$ in this group had a remarkably low OMT level ( $3 \%$ residual activity) suggesting that cosuppression occurred. This cosuppression event appeared to be relatively infrequent for transformants with the fulllength OMT sequence (one plant out of 20) in contrast with plants expressing shorter OMT sequences, whose expression led to a higher proportion of plants with depleted OMT activity (Figure 4, populations C,E,G,I). On the other hand, the expression of the full-length sequence in antisense orientation led to a reverse pattern: 15 plants of this population exhibited a significantly reduced OMT activity with the most inhibited transformants displaying only $3 \%$ residual activity. With all the gene fragments expressed in both directions, strong inhibition in the transformants was observed in a portion of the plants indicating that sense or antisense expression may lead to gene silencing, as already observed for other plant genes. It is also noteworthy that the full-length and near full-length sequences were the most efficient in antisense orientation (populations $B$ and $D$ ) and that the sense expression of the near full-length sequence deleted at the $5^{\prime}$ and $3^{\prime}$ 

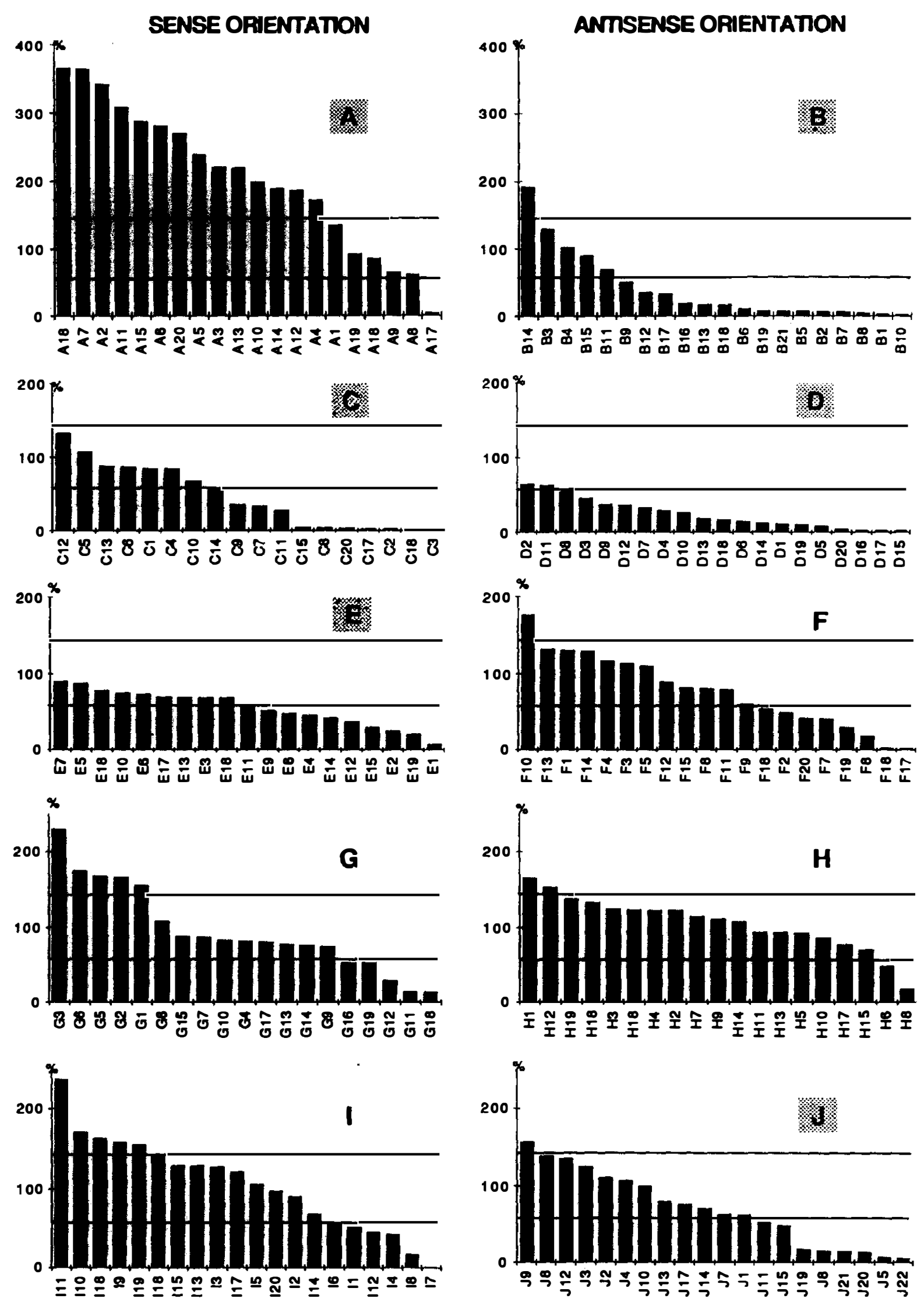
extremities (population C) was the most potent for gene silencing, leading to co-suppression in half of the transformants. A majority $(80 \%)$ of plants with modulated activity (increased in $A$, decreased in other populations) exhibited GUS activity, thus suggesting that the changes in OMT activity generally resulted from T-DNA gene expression.

\section{OMT inhibition during the development of transformants}

Selected plantlets were grown in the greenhouse and 3 month-old plants were analyzed for OMT activity. Values measured in adult stems were compared with those measured at the plantlet stage (Figure 5). The results demonstrate that, in control plants, OMT activity fluctuates similarly at adult and plantlet stages. In plants transformed with full-length OMT sequence in the sense (A plants) or antisense (B plants) orientation, similar levels of OMT activity were also observed at both stages of development and under the different growth conditions. This was clearly not the case, however, in plants from other groups of transformants in which low OMT activity were observed at the plantlet stage but whose activity at the adult stage reached levels comparable to control values. A and B plants with marked changes in OMT activity at the adult stage were further analyzed.

\section{Molecular analysis of transformants}

Individuals chosen from populations $A$ and $B$ were characterized by Southern blot experiments and their progeny was analyzed after self-fertilization. For most plants, the segregation of the kanamycin resistance trait was in accordance with the molecular data (data not shown). Interest-

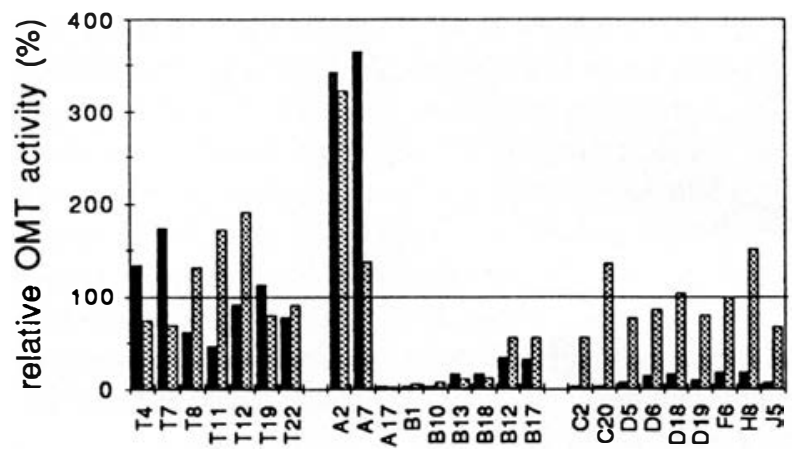

Figure 5. Comparison of OMT activity between 5-week-old plantlets (solid bars) cultured in vitro and the corresponding adult plants (shaded bars) grown for 3 additional months in the greenhouse. ingly, in the progeny of parents with strongly modulated OMT activity, a number of plants displayed similar changes in enzyme activity (data not shown). Taken together, these results demonstrate that the transgenes were stably integrated in the plant genome and are transmitted to the progeny.

The steady-state level of endogenous and transgene mRNAs was analyzed by Northern blot. For this purpose, we used three types of probes with different specificities (Figure 6).

(i) A probe derived from OMT cDNA hybridizing to sense or antisense transcripts from the OMT transgene and also to those from the resident OMT gene.

(ii) A probe derived from the $35 \mathrm{~S}$ polyadenylation signal specific to the OMT transgene transcripts.

(iii) A probe synthesized from the vidA gene.

The level of uidA transcripts was used as an internal control of T-DNA expression with no interference with the expression of plant homologous sequences. Finally, hybridization was carried out with a $25 S$ rRNA probe to ensure that the same quantity of total RNA had been loaded on the gel for each sample (data not shown).

Figure 6 presents the data obtained for A and B plants which displayed OMT alterations at the adult stage. The 35S terminator probe allowed specific detection of the transcripts of the OMT transgene only in some transformants, those with a high level of OMT activity arising from OMT gene overexpression (plants $A_{2}, A_{5}, A_{6}, A_{7}$ ). As expected, no signal was detected in untransformed controls (T plants), but more surprisingly, a very weak signal or no
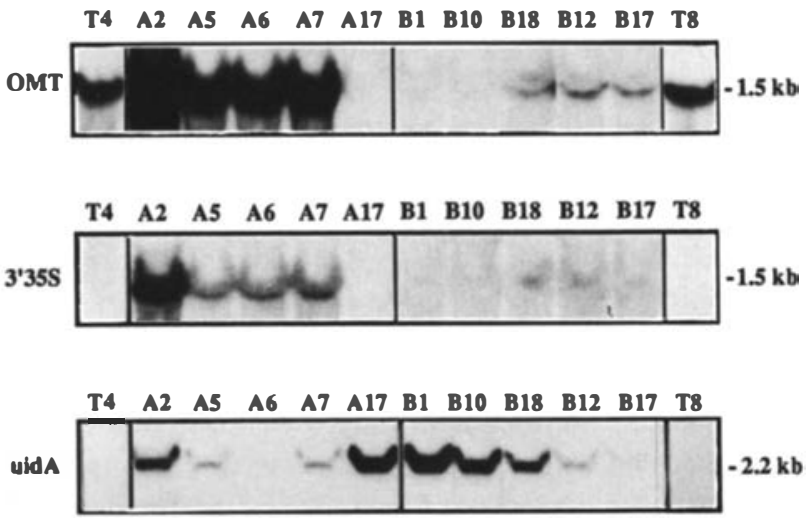

Flyers 6. RNA blot analysis of gene expression in stem tissues of adult control and transgenic piants.

Stem RNAs were hybridized with probes corresponding to the OMT cDNA (upper panel) or the $35 S$ polvadenylation signal (middle panel) or the vidA coding region (bottom panel).

Figure 4. OMT activity in sense and antisense transgenic plants transformed with the different constructs shown in Figure 2.

Enzyme activity was measured in 5-week-old, in vitro cultured plantlews, and expressed as a percentage of the mean value of the control population. Horizontal lines correspond to the standard deviation of the OMT values of control population. The shaded letters indicate the populations which significantly differ from the control. 


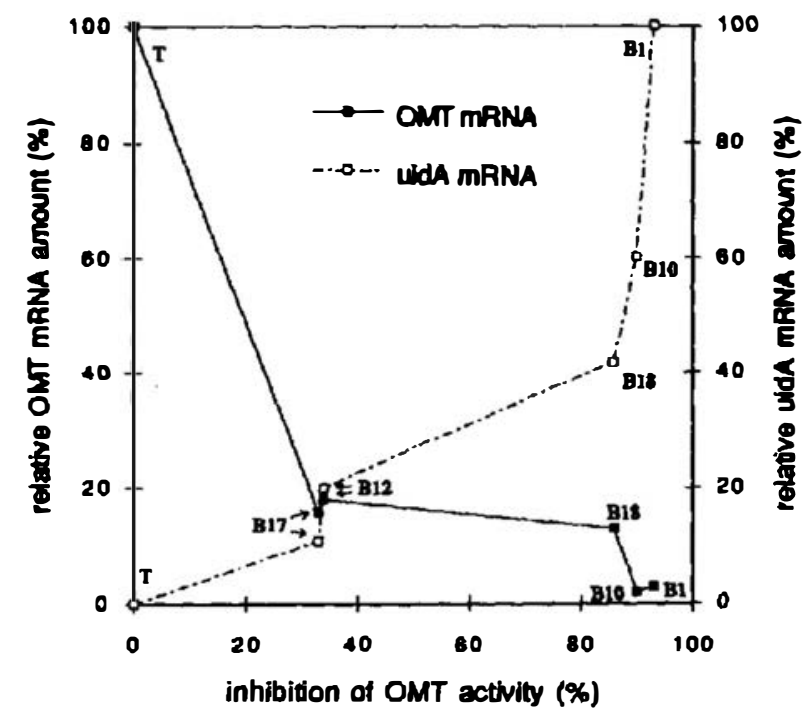

Figure 7. Relationship between OMT inhibition level, OMT MRNA and uidA mRNA amounts in stem tissue of antisense-inhibited transformants. mRNA was quantified by profile analysis of the Northem blots (Figure 6) using a Bio-Imaging Analyzer. Mean value from four control plants (T) was taken as 100\% OMT mRNA. In B plants (Figure 6, upper panell, endogenous and transgene OMT transcripts could be discriminated because the latter is longer, due to the presence of an additive polyadenylation signal isee Figure 21. uidA mRNA level was the highest in $B_{1}$ plant and was taken as $100 \%$ value.

signal at all was detected in the most highly inhibited plants $\left(A_{17}, B_{1}, B_{10}, B_{18}, B_{12}, B_{17}\right)$. OMT mRNAs (Figure 6 . OMT probel were found in untransformed stem (T) and in overexpressing plants $\left\langle A_{2}, A_{5}, A_{6}, A_{7}\right\rangle$. When compared with the results obtained with the transgene-specific probe, the higher intensity of the bands is consistent with the cumulative detection of both the transgene (sense or antisense) and the resident gene transcripts on the same blots. The signal was undetectable or very weak in plants displaying a high degree of OMT inhibition $\left.\right|_{17}$ and $B$ plants, OMT probel. On the contrary, the intensity of the bands revealed by the uidA probe is very high in the most inhibited plants $\left\{A_{17}, B_{1}, B_{10}, B_{18}\right\}$ indicating that $O M T$ inhibition resulted from high level of transgene expression. The amounts of OMT and vidA transcripts were estimated from band intensity and plotted against OMT activity (Figure 7). OMT mRNA amount appeared directly correlated to OMT activity whereas a reverse correlation was observed for uidA transcript amount. This suggests that, in inhibited plants, there is a direct correlation between the level of $T$ DNA expression measured by uidA transcript amount and the degree of OMT inhibition.

These data demonstrate that, in the most strongly inhibited plants transformed with the OMT sequence in sense $\left(A_{17}\right)$ or antisense ( $B$ plants) orientation, both endogenous and transgenic OMT transcripts disappeared simultaneously. To investigate whether this phenomenon is controlled by the relative level of expression of the two
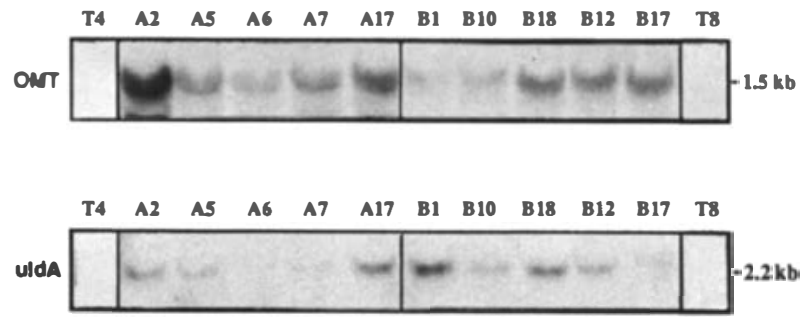

Fin B. RNA blot analysis of gene expression in leaf tissue of adult control and transgenic plants.

Leaf RNAs were hybridized with an OMT CDNA probe (upper panel) and a uidA probe (bottom panel).

types of homologous transcripts, we analyzed gene expression in the leaves of the same transgenics. Previous studies had shown that a lower enzyme activity and a lower level of OMT transcript accumulation occurred in leaf tissues, compared with the levels measured in stem tissues (Jaeck et al., 1992). Figure 8 presents blots of leaf RNAs hybridized to the OMT and vidA probes. In controls (T), levels of OMT mRNA were below the limit of detection, thus confirming a very low level of constitutive expression in leaf tissues. In leaves of overexpressing plants (plants $A_{2}, A_{5}, A_{6}, A_{7}$ ) the OMT probe detected the presence of OMT transgene transcripts in leaves as in the stems. However, for plants highly inhibited $\left(A_{17}\right.$ and $B$ plants) high levels of transgene OMT transcript accumulation were found in leaves whereas no transcript was detectable in the stem of the same transformants. When uidA gene expression was examined, it appeared that many of the plants which showed uidA expression in stems (Figure 6) also accumulated uidA transcripts in leaf tissues to the same relative extent. Taken together, these data clearly show that T-DNA genes are expressed in different tissues of the transformants and that the relative activity of OMT genes determines the efficiency of antisense effect.

The accumulation of OMT transgene transcripts was particularly high in the leaves of plant $A_{17}$, which displayed a co-suppression phenotype in the stem. OMT activity in leaf tissues of this transformant was found to be about eight-fold higher than the mean value of control plants (not shown), in agreement with the level of OMT transcript accumulation which was similar to that measured in other A plants overexpressing OMT enzyme. Thus these data demonstrate that in a given transformant, sense transgene expression may have opposite consequences in the different organs of the plant.

Appearance of a novel lignin in plants with reduced OMT activity

Plants with high or low OMT activity were indistinguishable from the controls at all stages of development. In particular, nocoloration was observed in lignified tissues of transgenic plants, in contrast to the situation in anti-CAD tobacco with 
reduced CAD activity (Halpin et al., 1994) and in natural mutants of maize and sorghum (Kuc and Nelson, 1964; Porter et al., 1978). Transverse sections from the stem of plants exhibiting a wide range of OMT levels were stained with Wiesner and Maüle solutions. Wiesner stain is known to react with cinnamaldehyde residues in lignin and the color intensity roughly reflects the total lignin content (Monties, 1989). No difference was detected with this stain between control and inhibited plants (Figure 9a and b) indicating no important variation in lignin quantity. In contrast, the Maule reaction, which is specific for free syringyl units (Monties, 1989), revealed striking variations in staining intensity (Figure 9c-h). Xylem and phloem tissues of control plants (Figure $9 \mathrm{c}$ and e) and of an overexpressing plant (Figure $9 \mathrm{~g}$ ) stained bright red.

In inhibited plants a good correlation was found between the intensity of the red stain and the level of OMT residual activity: the red color turned orange and yellow when OMT decreased (compare Figure 9d, $f$ and $h$ from plants $B_{18}, B_{10}$ and $A_{17}$ which had $12 \%, 8 \%$ and $2 \%$ residual activity, respectively, Table 1). These data strongly suggest that OMT inhibition markedly decreased the syringyl content of lignin without significantly affecting the amount of total lignin.

\section{Chemical analysis of transgenic lignin}

To confirm the above observations lignin from control and transgenic plants was analyzed by the thioacidolysis method. This procedure has the major advantage of preserving the C6-C3 skeleton characteristic of lignin monomers (Monties, 1989) and discriminates between products recovered from guaiacyl (G) and syringyl (S) units involved in $\beta-0-4$ bonds (Lapierre et al., 1986). Both unit types being major constituents of angiosperm lignin, their molar ratio $(S / G)$ is a characteristic feature of lignin. Figure 10 shows typical gas chromatography profiles obtained from a control $\left(T_{12}\right)$ and a transgenic plant $\left(B_{1}\right)$ which had only $6 \%$ residual OMT activity. In the inhibited plant a sharp decrease in the syringyl peak and the appearance of a new peak corresponding to the $5-\mathrm{OH}$ guaiacyl unit (Lapierre et al., 1988) were observed as compared with the control profile. Most interestingly, the same situation has been reported in a bm3 natural mutant of maize (Lapierre et al., 1988) which had a low level of OMT activity (Grand et al., 1985). Several transformed and untransformed plants with varying levels of OMT activity were analyzed and the data are presented in Table 1. The total amount of lignin was estimated by Klason's method and found to be similar in control and transgenic plants. Thus, as already suggested by our observations with Wiesner's stain (Figure 9), OMT inhibition did not significantly affect lignin quantity. Chemical analysis also confirmed that the syringyl unit biosynthesis is profoundly affected by OMT inhibition.
Indeed, the S/G ratio measured in transgenic lignin of the most inhibited plants is less than one-tenth of the value determined in control plants. The four control plants were chosen because they were representative of natural fluctuations in OMT activity. Their S/G ratio was found to be rather constant and close to 1 (Table 1). It is also noteworthy that an increase in OMT activity due to overexpression of the OMT gene in plant $A_{2}$, had no significant effect on lignin composition, indicating that 0 -methylation is not a rate-limiting step in lignin monomer biosynthesis.

When $S / G$ values measured from plants showing a range of OMT reduction were compared, a direct correlation between the level of OMT inhibition and the amplitude of the effects on lignin synthesis was found: when OMT activity reached $56 \%$ of the control mean value (plant $B_{17}$, Table 1) no effect on $S / G$ and no $5-O H$ G units were observed; when OMT activity fell to $12 \%$ of the control (plant $B_{18}$ ) the $S / G$ value was decreased by threefold and a significant amount of $5-\mathrm{OH} \mathrm{G}$ was detected; finally, for residual activity of $8 \%$ or less (plants $B_{10}, B_{1}$ and $A_{17}$ ) $S$ quantities were strongly reduced, $S / G$ ratios were very low and the highest amounts of $5-\mathrm{OH} \mathrm{G}$ were measured. Moreover, the quantities measured for 5-OH $\mathrm{G}$ and $\mathrm{S}$ units were negatively correlated and this is in accordance with expectation for derivatives of, respectively, the substrate and the product of an OMT-catalyzed reaction (see Figure 1).

In contrast to the steep decrease in S unit content, $\mathbf{G}$ content was not reduced in transgenic lignin, indicating that the first methylation step leading to ferulic acid was not inhibited. On the contrary, slightly higher amounts of $G$ unit were measured in several plants. A similar observation has been made in the $b m 3$ mutant of maize (Lapierre et al., 1988) and represents another feature common to lignin of engineered tobacco and of natural maize mutants. Taken together, these data demonstrate that the modulation of OMT activity in transgenic plants influences lignin composition directly as already observed for natural mutations.

\section{Diecussion}

By using various OMT gene constructs we have demonstrated that the ectopic expression of OMT gene fragments in sense or antisense orientation profoundly affects the expression of the endogenous OMT tobacco gene. Molecular analysis of the transformed plants showed that the transgenes were stably inserted in the plant genome and were transferred to the progeny as a Mendelian trait. At the in vitro plantlet stage, the efficiency of the modulation, as measured by changes in OMT activity, was shown to depend on the nature of the construct used. The effects of transformation on gene expression dramatically changed during development and, at the adult stage, these effects were only maintained in plants transformed with the com- 

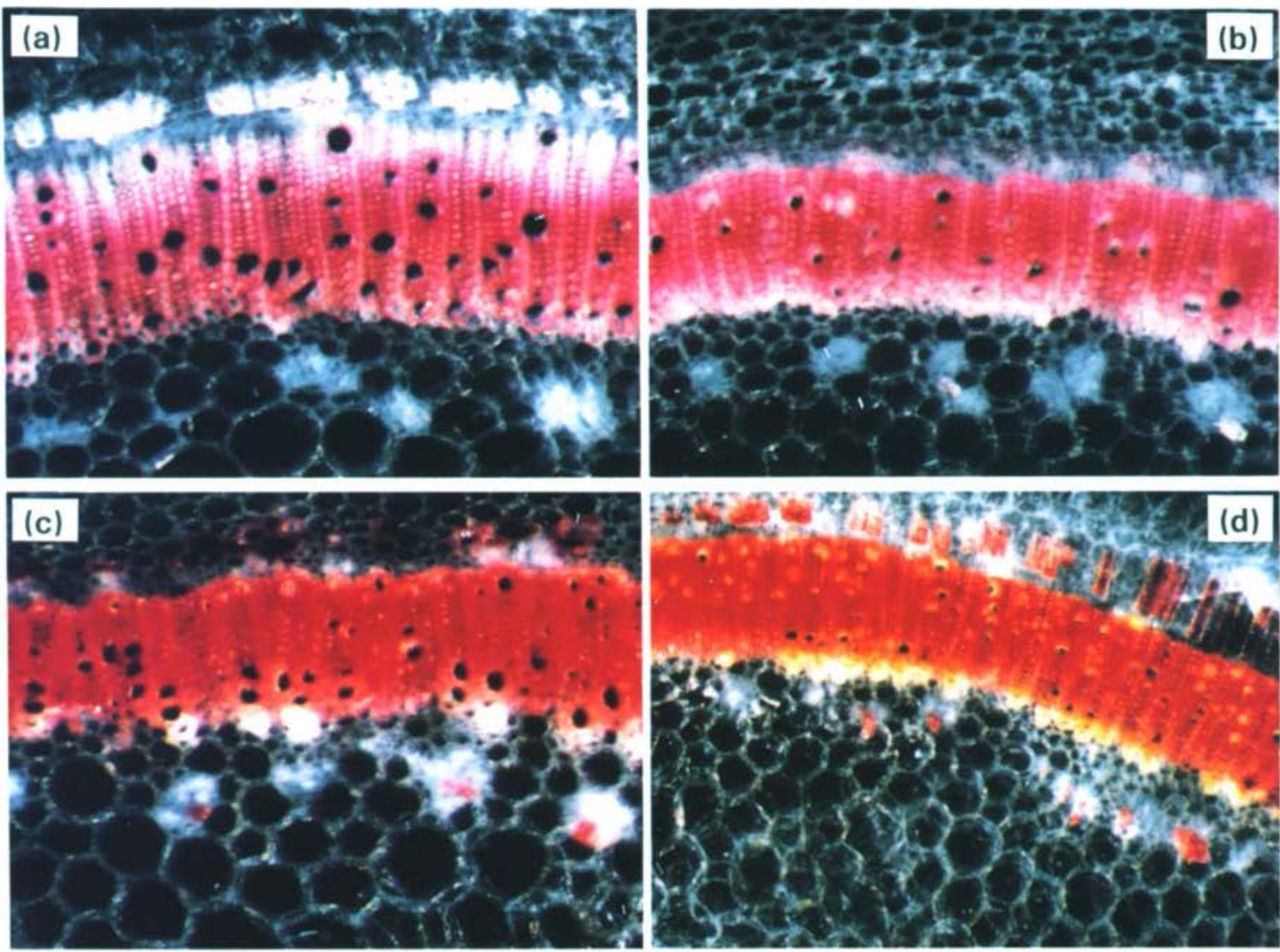

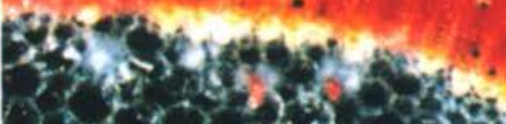
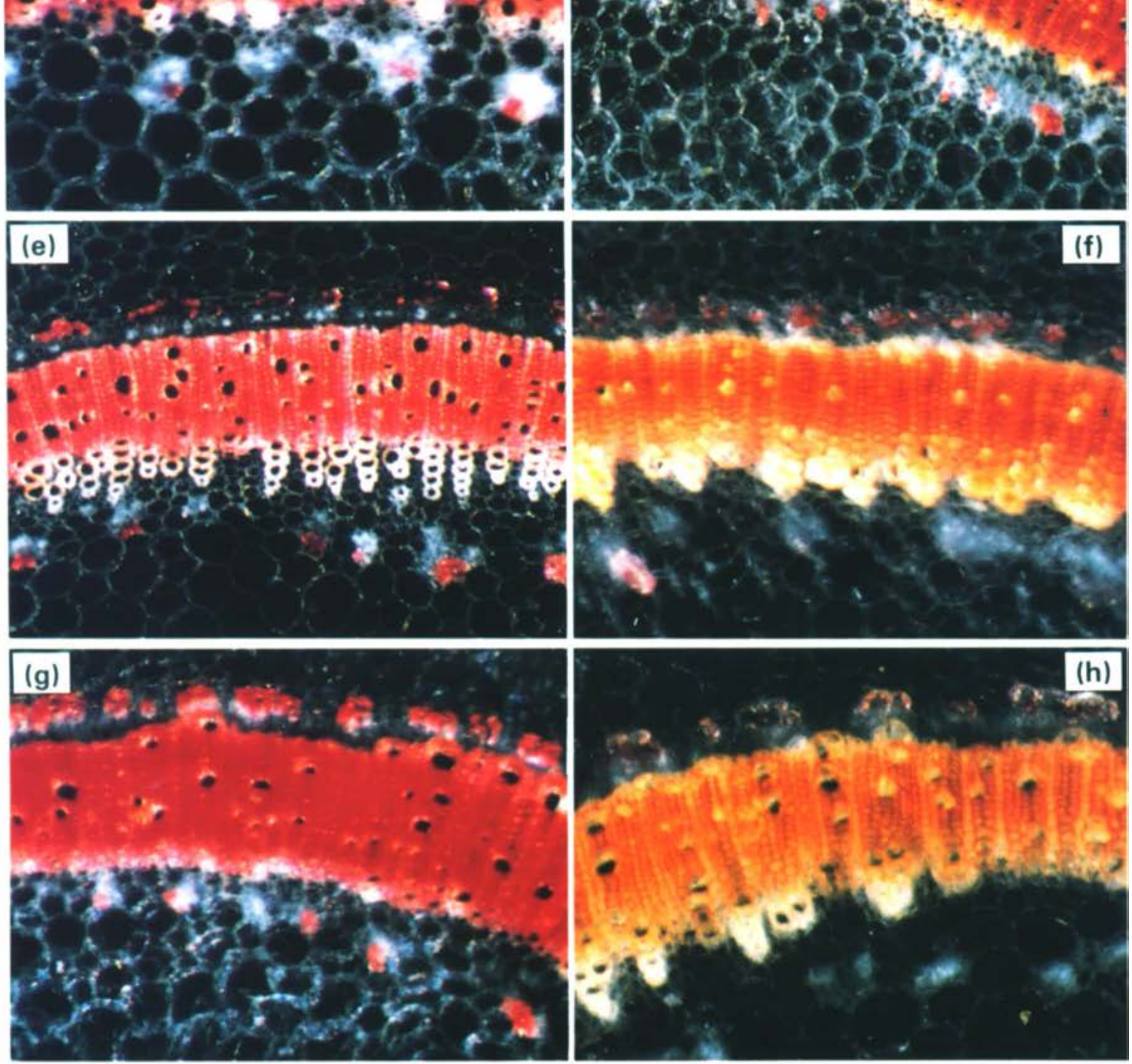
plete OMT sequence. Even though the mechanism underlying the differential efficiency of ectopic sequences is not known, these observations are of importance for the use of OMT as a target for lignin manipulation.

By histochemical and chemical methods, OMT inhibition was shown to change the nature of lignin dramatically without affecting the total quantity of lignin. From analysis of plants with varying degrees of OMT inhibition, it appeared that a threshold of $80-90 \%$ reduction is necessary to affect lignin composition. These data suggest that, in

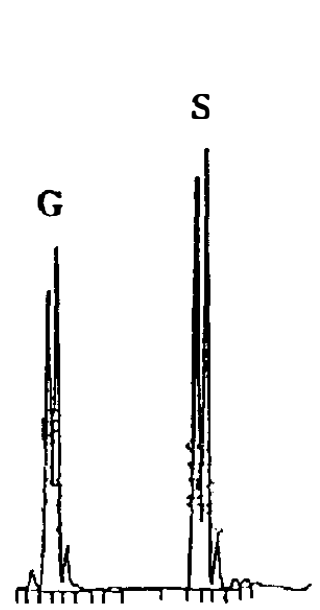

T12

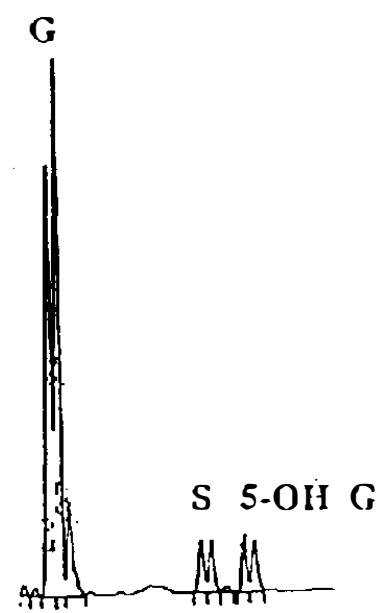

B1
Figure 10. Gas chromatograms showing the main degradation products recovered from thioacidolysis of lignin of a control plant $\left(T_{12}\right)$ and an antisense transformant $\left(B_{1}\right)$ with very low residual activity.

For each degradation product, erythro and threo isomers are observed. control plants, 0-methylation is not a rate-limiting step in lignin biosynthesis. Consistently, the overexpression of the OMT gene had no detectable effect on lignin. Thus, transgenic plants should prove to be valuable tools to investigate regulation mechanisms controlling lignin biosynthesis. It should be stressed that the data of the present work contradict most of those obtained by introducing an heterologous OMT sequence into tobacco plants (Dwivedi et al., 1994; Ni et al., 1994). Ni et al. (1994) obtained one antisense transformant (out of seven) with $20 \%$ residual OMT activity compared with controls and with a reduced lignin content but no change in lignin composition. We never found a significant decrease in lignin content of transformants, even in plants with only $2-3 \%$ residual enzyme activity (Table 1). On the other hand, Dwivedi et al. (1994) obtained one transformant (out of four) with $54 \%$ residual OMT activity, which displayed no change in lignin content and had a $\mathrm{S} N$ ratio of $\mathbf{0 . 7 7}$. This is 10 -fold higher than the 0.07 value determined in the present study for the most inhibited transgenics (Table 1). The spectacular decrease we found in S/G ratio demonstrates unequivocally the effects of OMT manipulation on lignin composition. Moreover, the thioacidolysis method enabled us to demonstrate the accumulation of 5-OH G. This component cannot be detected with the alkaline nitrobenzene oxidation procedure used in the other studies (Dwivedi et al., 1994; $\mathrm{Ni}$ et al., 1994).

The study of plants with varying degrees of inhibition enabled us to establish a direct correlation between the quantity of OMT mRNA detected on blots and the level of residual enzyme activity. Moreover, in stems of inhibited

Table 1. Chemical analysis of lignin

\begin{tabular}{|c|c|c|c|c|c|c|}
\hline Plant & \%ОМТ & Klason & G & $\mathbf{S}$ & $5-\mathrm{OH} \mathrm{G}$ & S/G \\
\hline$A 2$ & 322 & nd & $177 \pm 4.5$ & $175 \pm 5.8$ & - & 1.0 \\
\hline $\mathrm{T} 12$ & 191 & nd & $160 \pm 4.7$ & $149 \pm 3.6$ & - & 0.93 \\
\hline $\mathrm{T} 11$ & 172 & $17.7 \pm 0.09$ & $148 \pm 4.2$ & $159 \pm 2.4$ & - & 1.1 \\
\hline T19 & 80 & $19.1 \pm 0.09$ & $159 \pm 8.7$ & $152 \pm 13$ & - & 0.96 \\
\hline $\mathrm{T7}$ & 69 & nd & $154 \pm 3.9$ & $169 \pm 2.5$ & - & 1.1 \\
\hline B17 & 56 & nd & $112 \pm 1.8$ & $112 \pm 2.5$ & - & 1.0 \\
\hline B18 & 12 & $18.7 \pm 0.05$ & $178 \pm 1.7$ & $52 \pm 1.2$ & $3.8 \pm 1.5$ & 0.30 \\
\hline B10 & 8 & $18.8 \pm 0.03$ & $196 \pm 1.4$ & $14 \pm 0.4$ & $9.9 \pm 0.1$ & 0.07 \\
\hline B1 & 6 & $17.6 \pm 0.03$ & $176 \pm 6.0$ & $13 \pm 0.9$ & $9.3 \pm 3.3$ & 0.07 \\
\hline A17 & 2 & $18.5 \pm 0.04$ & $172 \pm 3.0$ & $16 \pm 1.0$ & $8.9 \pm 0.3$ & 0.09 \\
\hline
\end{tabular}

Chemical analysis of lignin in adult transgenic and control plants with different levels of OMT activity (\% OMT). Total lignin content was estimated by Klason's method and is expressed as percentage of cell wall residues (nd, not determined). Monomeric composition of lignin was determined after thioacidolysis: G, guaiacyl unit; S, syringyl unit and 5-OH G, 5-OH guaiacyl unit. Unit amounts are expressed as $\mu$ moles per gram of Klason lignin.

Figure 9. Histochemical reactions on transverse stem sections of control and transgenic plants.

Wiesner's staining was performed on: (a) a control plant $\left(T_{12}\right)$; (b) an antisense transformant $\left(B_{7}\right)$ with reduced activity. Maule's staining was performed on: (c) and (e) control plants $\left(T_{19}\right.$ and $T_{11}$, respectively); (d) and (f) antisense transformants with different levels of $O M T$ inhibition ( $B_{19}$ and $B_{10}$, respectively); $(g)$ a sense overexpressing transformant $\left(A_{2}\right) ;(h)$ a sense inhibited transformant $\left(A_{17}\right)$. 
plants, a parallel disappearance of OMT transcripts originating from the resident gene and from the transgene occurred. But in those transgenics, the transgene RNA was detected in leaf tissues where the endogenous mRNA is produced in low quantity. Thus the relative extent of expression of each type of OMT sequence appears to be a critical parameter for inhibition.

In plants severely depleted in OMT activity, the amount of syringyl unit in lignin decreased and a new lignin unit, 5-OH G, appeared. The amplitude of these changes is a function of residual OMT activity in each plant and they are likely to arise from the effective inhibition of the second methylation step in the phenylpropanoid pathway (Figure 1). Surprisingly, the amount of $G$ unit in transgenic lignin was not affected, indicating that the first methylation step was not inhibited in vivo. These data show that another enzyme, with no sequence similarity with OMT and, consequently, unaffected by the transformation with OMT sequences, catalyzes ferulic acid synthesis. A good candidate might be caffeoyl-coA 0-methyltransferase which has been characterized in different plant species (Kühnl et al., 1989; Pakusch et al., 1989; Ye et al., 1994) and has been proposed to provide an alternative pathway for lignin synthesis (Ye et al., 1994). Indeed, enzyme activity methylating the caffeoyl-coA ester is present in untransformed and in transformed tobacco (Martz, unpublished) and could be responsible for the synthesis of the $G$ unit. On the other hand, the alteration of lignin composition of OMT inhibited plants demonstrates that the second methylation step leading to the $S$ unit is catalyzed by OMT and cannot be complemented by caffeoyl-coA 0 methyltransferase. This latter enzyme has been cloned recently (Schmitt et al., 1991; Ve et al., 1994) and the study of the effects of caffeoyl-coA 0-methyltransferase modulation by genetic transformation of wild tobacco or of OMT-engineered plants (double transformants) would be of great interest to evaluate the relative importance of the two enzymes in each of the two methylation steps involved in monolignol synthesis.

The inhibition of OMT activity in transgenic plants could prove useful to the genetic improvement of forage crops. Indeed, our data show that transgenic lignin resembles the lignin of mutants lines when compared with lignin of wild plants. Hence, one may assume that similar perturbations affect lignin synthesis in both cases. Therefore, one can expect to increase by genetic engineering the economic value of crops whose digestibility could be improved, as is the case for natural mutants of maize. Similarly, the alteration of lignin composition of woody species and particularly, the decreased content in methoxyl groups which give rise to polluting mercaptans during the pulping process, would be of great economic and ecological interest. On the other hand, the reduced proportion of syringyl unit in transgenic lignin is likely to lead to a more condensed polymer very rich in carbon-carbon linkages (Monties, 1989). Transgenic tobacco will enable us to test whether the synthesis of such a modified lignin offers a better protection to the plant against pathogen infection. Finally, the work described here represents one of the first examples demonstrating the feasibility of lignin manipulation by biotechnology.

\section{Experimental procedures}

\section{Vector construction}

All DNA recombinant techniques were performed essentially as described by Sambrook et al. (1989). The binary vector pFB8 was derived from pBI 101 (Jefferson et al., 1987). The 420 bp fragment of CaMV 35S RNA promoter corresponding to bp 7016--7436 of CM 1841 (Gardner et al., 1981) was inserted at the Smal site in front of the uid $A$ gene to produce a transcriptional fusion. A $1.2 \mathrm{~kb}$ HindIII fragment of pRT99 (Töpfer et al., 1988) carrying the CAT gene flanked by the 420 bp CaMV $35 S$ promoter and terminator sequences was inserted at the HindIII site of the $\mathrm{pBI} 101$ polylinker. The CAT coding region has been deleted as a BamH fragment and the resulting vector pFB8 (Figure 2) carried three cassettes from the right to the left border of T-DNA: (i) the npt-ll gene for kanamycin resistance; (ii) the cassette for sense or antisense expression controlled by $35 S{ }^{\prime}$ and $3^{\prime}$ sequences; (iii) the uid $A$ gene, also driven by the $35 \mathrm{~S}$ promoter, as internal control.

The class I OMT cDNA fragment was isolated from a pKS II plasmid (Stratagene) containing the tobacco class I OMT CDNA, inserted at the EcoRl site. Different fragments of OMT I cDNA, depicted in Figure 2, were used:

(i) a full-length cDNA 1457 bp (EcoRV-Smal);

(ii) a 1217 bp (Hind III-Hind III) segment lacking the 5 ' untranslated region, the first 18 codons of the ORF, and 94 bp from the extreme 3' untranslated region;

(iii) a 710 bp (EcoRI-Hincll) fragment corresponding to the $5^{\prime}$ half of the cDNA;

(iv) a $430 \mathrm{bp}$ (Hincll-EcoRl) fragment corresponding to the 3' part of the ORF;

(v) a 300 bp (EcoRI-EcoRI) fragment carrying the last three codons of the ORF and the $3^{\prime}$ untranslated region.

All five DNA fragments were purified, blunt ended by filling in with the Klenow fragment of DNA polymerase I and ligated to the Smal site of pFB8. The orientation of the inserts was determined by restriction digestion of plasmids recovered from transformed Escherichia coli DH5 $\alpha$.

The binary vectors were transferred to Agrobacterium tumefaciens LBA4404 by the triparental mating procedure with pRK2013 (in E. coli HB101) as helper plasmid (Bevan, 1984). The integrity of the vectors was verified by analyzing total DNA from Agrobacterium according to the method of Dhaese et al. \{1979).

\section{Plant transformation and regeneration}

Tobacco (Nicotiana tabacum cv. Samsun NN) was transformed by a modification of the leaf disk method (Horsch et al., 1985). Murashige and Skoog (MS) medium was used with an $\mathrm{NH}_{4} \mathrm{NO}_{3}$ concentration lowered twofold. Kanamycin (Sigma) at $150 \mathrm{mg}$ $\mathrm{ml}^{-1}$ and cefotaxime (Duchefa) at $350 \mathrm{mg} \mathrm{ml}^{-1}$ were used as selective agents during the in vitro regeneration and propagation 
procedures. Calli formation and shoot differentiation were carried out on MS medium supplemented with 6-benzylaminopurine (Serva) (2 mg ml $\mathrm{m}^{-1}$ ) and naphthalene acetic acid (Serva) $\left(0.05 \mathrm{mg} \mathrm{ml}^{-1}\right.$ ). Rooting was obtained on MS medium with half sucrose concentration $\left(15 \mathrm{~g} \mathrm{I}^{-1}\right)$. Transformed plants were grown in vitro for 5 weeks under a light-dark regime of $12 \mathrm{~h}(20-30 \mu \mathrm{E}$ $\left.\mathrm{m}^{-2} \mathrm{sec}^{-1}, 24^{\circ} \mathrm{C}\right)-12 \mathrm{~h}\left(20^{\circ} \mathrm{C}\right)$, then the basal part of the stem was assayed for OMT activity, and the upper part was micropropagated under the same conditions. For each construct, 20 independent transformants were regenerated, as well as 21 untransformed plants as controls (without kanamycin selection).

Once tested for OMT activity, subcultured plantlets of the clones of interest were transferred to the greenhouse and cultivated in soil under a light-dark period of $16 \mathrm{~h} / 8 \mathrm{~h}, 22 \pm 4^{\circ} \mathrm{C}$, till flowering. Plants were allowed to self-pollinate and $F_{1}$ seeds were harvested and further selected on germination medium containing kanamycin.

\section{Enzyme assays}

OMT and GUS assays were conducted on 5-week-old plantlets regenerated in vitro. The bottom of the stem (1 cm high) was ground in liquid nitrogen, extracted with $100 \mathrm{mM}$ sodium phosphate buffer $\mathrm{pH} 7.5,10 \mathrm{mM} D T T(2 / 1 \mathrm{v} / \mathrm{w})$, with the addition of polyclar AT (Serva) and quartz. The crude extract was clarified by centrifugation and filtered on glass wool. For OMT assay, $50 \mu$ of the protein extract was added to $1 \mathrm{ml}$ phosphate buffer containing $3 \mathrm{mM}$ caffeic acid, $50 \mu \mathrm{M}$ tritiated S-adenosyl-L-methionine $\left(0.1 \mu \mathrm{Ci} \mathrm{ml} l^{-1}\right)$ and incubated for $1 \mathrm{~h}$ at $37^{\circ} \mathrm{C}$ in scintillation vials. The reaction was stopped with $100 \mu / 9 \mathrm{M} \mathrm{H}_{2} \mathrm{SO}_{4}, 5 \mathrm{ml}$ NA scintillation solution (Beckman) was mixed in by vortexing for $45 \mathrm{sec}$, and the radioactivity of ferulic acid extracted by the scintillation solution, was counted in a Beckman LS 9000 apparatus. When OMT activity was measured on adult plants, an additional step of exclusion chromatography on PD-10 columns (Pharmacia) was performed to eliminate the endogenous $a$ diphenolic substrates. GUS fluorimetric tests were carried out on the same samples according to the procedure of Jefferson et al. (1987). The protein content was determined by the method of Bradford (1976) using the Bio-Rad reagent.

\section{RNA analysis}

RNA was isolated from 1-2 $\mathrm{g}$ frozen plant material by phenol extraction (Howell and Hull, 1978) followed by selective precipitation with $4 \mathrm{M} \mathrm{LiCl} \mathrm{(Venwoerd} \mathrm{et} \mathrm{al.,} \mathrm{1989).} \mathrm{For} \mathrm{Northern} \mathrm{blots,} \mathrm{RNA}$ samples $(10 \mu \mathrm{g})$ separated on formaldehyde gels were transferred on to Hybond $\mathrm{N}$ filters (Amersham) and hybridized to randomly primed radiolabeled probes synthesized from: (i) 1217 bp OMT cDNA; (ii) 230 bp $35 \mathrm{~S}$ polyadenylation signal; (iii) 1800 bp uidA coding region; (iv) 300 bp ribosomal $25 S$ gene (as a control of the amount of RNA loaded). mRNA was quantified on Northern blots using a Fujix Bio-Imaging Analyzer (BAS 1000 MacBas).

\section{Histology}

Stem sections were hand cut with a razor blade from the 19th or 20th internode of plants grown for 3 months in the greenhouse, and treated with hot ethanol to eliminate tissue pigmentation. Wiesner and Maüle reactions were performed according to standard protocols (Strivastava, 1966). For Maüle staining, stem sections were immersed for $5 \mathrm{~min}$ in $1 \% \mathrm{KMnO}_{4}$, rinsed, destained in $30 \% \mathrm{HCl}$, washed and mounted in concentrated $\mathrm{NH}_{4} \mathrm{OH}$. For the Wiesner reaction, stem sections were incubated for $2 \mathrm{~min}$ in phloroglucine solution ( $2 \%$ in ethanol/water $95 / 5 \mathrm{v} / \mathrm{v}$ ), then mounted in $50 \% \mathrm{HCl}$. Bright field photographs were taken at sevenfold magnification with a Schimadzu SMZ-U $300 \mathrm{~m}$ (Nikon) binocular microscope.

\section{Chemical analysis of lignin}

Thioacidolysis method and product separation by gas chromatography have been described previously (Lapierre et al., 1986, 1988).

\section{Acknowledgments}

We thank Dr K. Richards for careful reading of the manuscript. We are grateful to P. Keltz and R. Wagner for taking good care of tobacco plants. This work was supported by a grant from the Commission of European Communities (ECLAIR-OPLIGE AGRE 0021).

\section{References}

Bevan, M. (1984) Binary Agrobacterium vectors for plant transformation. Nucl. Acids Res. 12, 8711-8721.

Bradford, M.M. (1976) A rapid and sensitive method for the quantitation of microgram quantities of protein-dye binding. Anal. Biochem. 72, 248-254.

Bugos, R.C., Chiang, V.L.C. and Campbell, W.H. (1991) CDNA cloning, sequence analysis and seasonal expression of ligninbispecific caffeic acid/5-hydroxyferulic acid 0-methyltransferase. Plant Mol. Biol. 17, 1203-1215.

Buxton, D.R. and Russel, J.R. (1988) Lignin constituents and cell wall digestibility of grass and legume stems. Crop Sci. 28, 553-558.

Chapple, C.C.S., Vogt, T., Ellis, B. and Somerville, C.R. (1992) An Arabidopsis mutant defective in the general phenylpropanoid pathway. Plant Cell, 4, 1413-1424.

Cherney, J.H., Cherney, D.J.R., Akin, D.E. and Axtell, J.D. (1991) Potential of brown-midrib, low lignin mutant for improving forage quality. Adv. Agron. 46, 157-198.

Collazo, P., Montoliu, L., Puigdomenech, P. and Rigau, J. (1992) Structure and expression of the lignin 0-methyltransferase gene from Zea mays L. Plant Mol. Biol. 20, 857-867.

Dean, J.F.D. and Eriksson, K.-E.L. (1992) Biotechnological modification of lignin structure and composition in forest trees. Holzforschung, 46, 135-147.

Dhaese, P., De Greve, H., Decraemer, H., Schell, J. and Van Montagu, M. (1979) Rapid mapping of transposon insertion and deletion mutations in the large Ti-plasmids of Agrobacterium tumefaciens. Nucl. Acids Res. 7, 1837-1849.

Dumas, B., Van Doorsselaere, J., Gielen, J., Legrand, M., Fritig, B., Van Montagu, M. and Inze, D. (1992) Nucleotide sequence of a complementary DNA encoding 0-methyltransferase from poplar. Plant Physiol. 98, 796-797.

Dwivedi, U.N., Campbell, W.H., Yu, J., Dalta, R.S.S., Bugos, R.C., Chiang, V.L. and Podlla, G.K. (1994) Modification of lignin biosynthesis in transgenic Nicotiana through expression of an antisense 0-methyltransferase gene from Populus. Plant Mol. Biol. 26, 61-71.

Flavell, R.B. (1994) Inactivation of gene expression in plants as a consequence of specific sequence duplication. Proc. Natl Acad. Sci. USA, 91, 3490-3496.

Gardner, R.C., Howarth, A.J., Hahn, P., Brown-Luedi, M., Shepherd, R.J. and Messing, J. (1981) The complete nucleotide sequence 
of an infectious clone of cauliflower mosaic virus by $\mathrm{M} 13 \mathrm{mp} 7$ shotgun sequencing. Nucl. Acids Res. 9, 2871-2888.

Gowri, G., Bugos, R.C., Campbell, W.H., Maxwell, C.A. and Dixon, R.A. (1991) Stress responses in alfalfa (Medicago sativa L.).X. Molecular cloning and expression of S-adenosyl-Lmethionine:caffeic acid 3-O-methyltransferase, a key enzyme of lignin biosynthesis. Plant Physiol. 97, 7-14.

Grand, C., Parmentier, P., Boudet, A. and Boudot, A.M. (1985) Comparison of lignins and of enzymes involved in lignification in normal and brown-midrib $(b \mathrm{~m} 3)$ mutant corn seedlings. Physiol. Végét. 23, 905-911.

Gray, J., Plcton, S., Shabbeer, J., Schuch, W. and Grierson, D. (1992) Molecular biology of fruit ripening and its manipulation with antisense genes. Plant Mol. Biol. 19, 69-87.

Grisebach, H. (1981) Lignins. In Biochemistry of Plants, Volume 7 (Stumpf, P.K. and Conn, E.E., eds). New York: Academic Press, pp. 457-478.

Halpin, C., Knight, M.E., Foxon, G.A., Campbell, M.M., Boudet, A.M., Boon, J.J., Chabbert, B., Tollier, M.-T. and Schuch, W. (1994) Manipulation of lignin quality by down-regulation of cinnamyl-alcohol dehydrogenase. Plant J. 6, 339-350.

Hermann, C., Legrand, M., Geoffroy, P. and Fritig, B. (1987) Enzymatic synthesis of lignin: purification to homogeneity of the three 0-methyltransferases of tobacco and production of specific antibodies. Arch. Biochem. Biophys. 253, 367-376.

Horsch, R.B., Fry, J.E., Hoffmann, N.L., Eichholtz, D., Rogers, S.G. and Fraloy, R.T. (1985) A simple and general method for transfering genes into plants. Science, 227, 1229-1231.

Howell, S.H. and Hull, R. (1978) Replication of cauliflower mosaic virus and transcription of its genome in turnip leaf protoplasts. Virology, 88, 468-481.

Jaeck, E., Dumas, B., Geoffroy, P., Favet, N., Inzé, D., Van Montagu, M., Fritig, B. and Legrand, M. (1992) Regulation of enzymes involved in lignin biosynthesis: induction of O-methyltransferase mRNAs during the hypersensitive reaction of tobacco to tobacco mosaic virus. Mol. Plant-Microbe Interact. 5, 294-300.

Jefferson, R.A., Kavanagh, T.A. and Bevan, M.W. (1987) GUS fusions: $\beta$-glucuronidase as a sensitive and versatile gene fusion marker in higher plants. EMBO J. 6, 3901-3907.

Jung, H.G. and Vogel, K.P. (1986) Influence of lignin on digestibility of forage cell wall material. J. Anim. Sci. 62, 1703-1712.

Kuc, J. and Nelson, O.E. (1964) The abnormal lignins produced by the brown-midrib mutants of maize. Arch. Biochem. Biophys. 105, 103-113.

Kühnl, T., Koch, U., Heller, W. and Wellmann, E. (1989) Elicitor induced S-adenosyl-L-methionine: caffeoyl-CoA 3-O-methyltransferase from carrot cell suspension cultures. Plant Sci. 60 , 21-25.

Kuroda, H., Shimada, M. and Higushi, T. (1975) Purification and properties of O-methyltransferase involved in the biosynthesis of Gymnosperm lignin. Phytochemistry, 14, 1759-1763.

Lapierre, C., Monties, B. and Rolando, C. (1986) Thioacidolysis of poplar lignins: identification of monomeric syringyl products and characterization of guaiacyl-syringyl rich fractions. Holzforschung, 40, 113-118.

Lapierre, C., Tollier, M.-T. and Monties, B. (1988) Mise en évidence d'un nouveau type d'unité constitutive dans les lignines d'un mutant de mais bm3. C. R. Acad. Sci. Paris, 307, 723-728.

Legrand, M. (1983) Phenylpropanoid metabolism and its regulation in disease. In Biochemical Plant Pathology (Calow, J.A. ed.). Chichester: John Wiley \& Sons Ltd, pp. 367-384.

Legrand, M., Fritig, B. and Hirth, L. (1978) O-diphenol Omethyltransferases of healthy and tobacco-mosaic-virusinfected hypersensitive tobacco. Planta, 144, 101-108.
Lowis, N.G. and Yamamoto, E. (1990) Lignin: occurrence, biogenesis and biodegradation. Ann. Rev. Plant Physiol. Plant Mol. Biol. 41, 455-496.

Matern, U. and Kneusel, R.E. (1988) Phenolic compounds in plant disease resistance. Phytoparasitica, 16, 153-170.

Matzke, M. and Matzke, A.J.M. (1993) Genomic imprinting in plants : parental effects and trans-inactivation phenomena. Ann. Rev. Plant Physiol. Plant Mol. Biol. 44, 53-76.

Mol, J.N.M., Krol, A.R.V.d., Tunen, A.J.V., Blokland, R.V., Lange, P.D. and Stuitie, A.R. (1990) Regulation of plant gene expression by antisense RNA. FEBS Lett. 268, 427-430.

Monties, B. (1989) Lignins. in Methods in Plant Biochemistry" Volume I (Dey, P.P. and Harborne, J.B., eds). London: Academic Press, pp. 113-157.

Napoli, C., Lemieux, C. and Jorgensen, R. (1990) Introduction of a chimeric chalcone synthase gene into petunia results in reversible co-suppression of homologous gene in trans. Plant Cell, 2, 279-289.

Ni, W., Paiva, N.L. and Dixon, R. (1994) Reduced lignin in transgenic plants containing a caffeic acid 0 -methyltransferase antisense gene. Transgenic Res. 3, 120-126.

Nicholson, R.L. and Hammerschmidt, R. (1992) Phenolic compounds and their role in disease resistance. Ann. Rev. Phytopathol. 30, 369-386.

Pakusch, A.E., Kneusel, R.E. and Matern. U. (1989) S-adenosylL-methionine:trans-caffeoyl-coenzyme A 3-0-methyltransferase from elicitor-treated parsley cell suspension cultures. Arch. Biochem. Biophys. 271, 488-494.

Pellegrini, L.O.G., Geoffroy, P., Fritig, B. and Legrand, M. (1993) Molecular cloning and expression of a new class of orthodiphenol-O-methyltransferases induced in tobacco leaves by infection or elicitor treatment. Plant Physiol. 103, 509-517.

Pillonel, C., Mulder, M.M., Boon, J.J., Forster, B. and Binder, A. (1991) Involvement of cinnamoyl-alcohol dehydrogenase in the control of lignin formation in Sorghum bicolor L. Moench. Planta, 185, 538-544.

Poeydomenge, D., Boudet, A.M. and Grima-Pettenati, J. (1994) A CDNA encoding S-adenosyl-L-methionine : caffeic acid 3-Omethyltransferase from Eucalyptus. Plant Physiol. 105, 749-750.

Porter, K.S., Axtell, J.D., Lechtenberg, V.L. and Colenbrander, V.F. (1978) Phenotype, fiber composition, and in vitro dry matter disappearance of chemically induced brown-midrib (bmr) mutants of Sorghum. Crop Sci. 18, 205-208.

Sambrook, J., Fritsch, E.F. and Maniatis, T. (1989) Molecular Cloning: A Laboratory Manual. Cold Spring Harbor, New York: Cold Spring Harbor Laboratory Press.

Schmitt, D., Pakusch, A.-E. and Matern, U. (1991) Molecular cloning, induction, and taxonomic distribution of caffeoyl-CoA 3-O-methyltransferase, an enzyme involved in disease resistance. J. Biol. Chem. 266, 17 416-17 423.

Smith, C.J.S., Watson, C.F., Ray, J., Bird, C.R., Morris, P.C. and Grierson, D. (1988) Antisense RNA inhibition of polygalacturonase gene expression in transgenic tomatoes. Nature, 334, 724-726.

Strivastava, L.M. (1966) Histochemical studies on lignin. Tappi, 49, 173-183.

Töpfer, R., Schell, J. and Steinbiss, H.H. (1988) Versatile cloning vectors for transient gene expression and direct gene transfer in plant cells. Nucl. Acids Res. 16, 8725.

Van der Krol, A.R., Lenling, P.E., Veenstra, J., Van der Meer, I., Koes, R.E., Gerats, A.G.M., Mol, J.N.M. and Stuitjo, A.R. (1988) An antisense chalcone synthase gene in transgenic plants inhibits flower pigmentation. Nature, 333, 866-869.

Van der Krol, A.R., Mur, L.A., De Lange, P., Mol, J.N.M. and Stuitje, 
A.R. (1990) Inhibition of flower pigmentation by antisense CHS genes: promoter and minimal sequence requirements for the antisense effect. Plant Mol. Biol. 14, 457-466.

Vance, C.P., Kirk, T.K. and Sherwood, R.T. (1980) Lignification as a mechanism of disease resistance. Ann. Rev. Phytopathol. 18, 259-288.

Verwoerd, T.C., Dekker, B.M.M. and Hoekema, A. (1989) A small scale procedure for the rapid isolation of plant RNAs. Nucl. Acids Res. 17, 2362.

Vignols, F., Rigau, J., Torres, M.A., Capollados, M. and Puigdomènech, P. (1995) The brown midrib3 (bm3) mutation in maize occurs in the gene encoding caffeic acid 0 methyltransferase. Plant Cell, 7, 407-416.

Watson, C.F. and Grierson, D. (1993) Antisense RNA in plants. In Transgenic Plants. Fundamentals and Applications (Hiatt,A. ed.). New York: Marcel Dekker, Inc., pp. 255-281.

Whotion, R. and Sedoroff, R. (1991) Genetic engineering of wood. Forest Ecol. Manage. 43, 301-316.

Ye, Z.-H., Kneusel, R.E., Matern, U. and Varner, J.E. (1994) An alternative methylation pathway in lignin biosynthesis in Zinnia. Plant Cell, 6, 1427-1439. 